\title{
Association of polymorphisms in the beta-2 adrenergic receptor gene with fracture risk and bone mineral density
}

\author{
A. G. Veldhuis-Vlug • L. Oei • P. C. Souverein • M. W. T. Tanck • \\ F. Rivadeneira • M. C. Zillikens • P. W. Kamphuisen • \\ A.H. Maitland - van der Zee - M. C. H. de Groot - A. Hofman • \\ A. G. Uitterlinden • E. Fliers • A. de Boer • P. H. Bisschop
}

Received: 20 October 2014 / Accepted: 20 February 2015 / Published online: 25 April 2015

(C) The Author(s) 2015. This article is published with open access at Springerlink.com

\begin{abstract}
Summary Signaling through the beta-2 adrenergic receptor (B2AR) on the osteoblast influences bone remodeling in rodents. In the B2AR gene, three polymorphisms influence receptor function. We show that these polymorphisms are not associated with fracture risk or bone mineral density in the UCP, Rotterdam Study, and GEFOS cohorts.
\end{abstract}

\footnotetext{
A. G. Veldhuis-Vlug $•$ E. Fliers $・$ P. H. Bisschop $(\bowtie)$

Department of Endocrinology and Metabolism, Academic Medical Center, University of Amsterdam, P.O. Box 22660, 1100

DD Amsterdam, The Netherlands

e-mail: p.h.bisschop@amc.uva.nl
}

L. Oei $\cdot$ F. Rivadeneira $・$ M. C. Zillikens $\cdot$ A. G. Uitterlinden Department of Internal Medicine, Erasmus Medical Center, Rotterdam, The Netherlands

L. Oei $\cdot$ F. Rivadeneira $\cdot$ A. Hofman $\cdot$ A. G. Uitterlinden Department of Epidemiology, Erasmus Medical Center, Rotterdam, The Netherlands

L. Oei $\cdot$ F. Rivadeneira $\cdot$ M. C. Zillikens $\cdot$ A. Hofman •

A. G. Uitterlinden

Netherlands Genomics Initiative (NGI)-sponsored Netherlands

Consortium of Healthy Aging (NCHA), Leiden, The Netherlands

P. C. Souverein - A. Maitland - van der Zee • M. C. H. de Groot

A. de Boer

Division of Pharmacoepidemiology and Clinical Pharmacology, Department of Pharmaceutical Sciences, Utrecht Institute for Pharmaceutical Sciences, Utrecht University,

Utrecht, The Netherlands

M. W. T. Tanck

Department of Clinical Epidemiology, Biostatistics and Bioinformatics, Academic Medical Center, University of Amsterdam, Amsterdam, The Netherlands

P. W. Kamphuisen

Department of Vascular Medicine, University Medical Center Groningen, University of Groningen, Groningen, The Netherlands
Introduction Signaling through the beta-2 adrenergic receptor (B2AR) on the osteoblast influences bone remodeling in rodents. In the B2AR gene, three polymorphisms are known to influence receptor function in vitro and in vivo (rs1042713, rs1042714, and rs1800888). We examined the role of these polymorphisms in the B2AR gene on human bone metabolism.

Methods We performed nested case-control studies to determine the association of these polymorphisms with fracture risk in the Utrecht Cardiovascular Pharmacogenetics (UCP) cohort and in three cohorts of the Rotterdam Study. We also determined the association of these polymorphisms with bone mineral density (BMD) in the GEFOS Consortium. UCP contains drug-dispensing histories from community pharmacies linked to national registrations of hospital discharges in the Netherlands. The Rotterdam Study is a prospective cohort study investigating demographics and risk factors of chronic diseases. GEFOS is a large international collaboration studying the genetics of osteoporosis. Fractures were defined by ICD-9 codes 800-829 in the UCP cohort (158 cases and 2617 unmatched controls) and by regular X-ray examinations, general practitioner, and hospital records in the Rotterdam Study (2209 cases and 8559 unmatched controls). BMD was measured at the femoral neck and lumbar spine using dualenergy X-ray absorptiometry in GEFOS $(N=32,961)$.

Results Meta-analysis of the two nested case-control studies showed pooled odds ratios of $0.98(0.91-1.05, p=0.52), 1.04$ $(0.97-1.12, p=0.28)$, and $1.16(0.83-1.62, p=0.38)$ for the associations between rs1042713, rs1042714, and rs1800888 per minor allele and fractures, respectively. There were no significant associations of the polymorphisms and BMD in GEFOS.

Conclusion In conclusion, polymorphisms in the beta-2 adrenergic receptor gene are not associated with fracture risk or BMD. 
Keywords Beta-2 adrenergic receptor $\cdot$ Bone mineral density . Bone-brain-nervous system interactions · Fracture $\cdot$ Human association studies $\cdot$ Polymorphisms

\section{Introduction}

The sympathetic nervous system (SNS) influences bone remodeling in rodents by signaling through the beta- 2 adrenergic receptor (B2AR) on the osteoblast. Osteoblast-specific deletion of the B2AR decreased bone resorption and led to an increase in bone mineral density [1]. To date, it is uncertain whether this mechanism also exists in humans. Retrospective observational studies in humans on the association of betablockers and fracture risk reported conflicting results, yet a recent meta-analysis showed a reduction in fracture risk with a relative risk around 0.85 [2].

The B2AR is a G-protein coupled receptor (GPCR). Binding of a ligand to the receptor leads to activation of the enzyme adenylate cyclase and generation of cyclic adenosine monophosphate (cAMP). Ligand binding also leads to phosphorylation of GPCR kinases which promotes downregulation of the receptor [3]. The intronless B2AR gene is localized on chromosome 5q31-32 and encodes for a protein of 413 amino acids. In 1993, the first single nucleotide polymorphism (SNP) in the B2AR gene was reported [4], and since then, many more SNPs have been identified. Four SNPs are non-synonymous and three of these are in the coding region of the gene [5] on amino acid positions 16 (Arg16Gly; rs1042713), 27 (Gln27Glu; rs1042714), and 164 (Thr164Ile; rs1800888). The SNP on position 164 has not been found in humans homozygously and has a low minor allele frequency $(<5 \%)$ [6]. The B2AR gene is highly evolutionary conserved, the mouse and human gene are $88 \%$ similar (comparison based on amino acids), and this also applies to the region surrounding the polymorphisms.

In vitro [7, 8] and in vivo [9] experiments have shown that the Thr164Ile polymorphism lowers the binding affinity and activation of cAMP, leading to a signaling defect of the receptor. For the Arg16Gly and Gln27Glu polymorphisms, the Gly16 variant was shown to be more susceptible to agonistinduced downregulation whereas the Glu27 is more resistant. The Gly16 variant dominates the phenotype when both variants are present (reviewed in [10-13]). Clinical research has extensively shown an effect of B2AR gene polymorphisms in cardiovascular therapy [14] and asthma [15, 16], and there are reports of B2AR gene polymorphisms influencing obesity [17], healthy aging [18], bacterial meningitis [19], and Graves' disease [20].

Since these studies show that the function of the B2AR can be influenced by polymorphisms, we hypothesized that these polymorphisms in the B2AR gene could also have an effect on bone metabolism. To examine the role of beta-adrenergic signaling in human bone metabolism, we investigated the association of these polymorphisms in the B2AR gene with fracture risk in the Utrecht Cardiovascular Pharmacogenetics (UCP) cohort and the Rotterdam Study cohorts. We also investigated the association with bone mineral density (BMD) using the meta-analysis of genome-wide association (GWA) data of the GEFOS consortium.

\section{Materials and methods}

Study design

We conducted nested case-control studies to assess the influence of SNPs in the B2AR gene on fracture risk in the Utrecht Cardiovascular Pharmacogenetics cohort and the Rotterdam Study cohorts (www.epib.nl/research/ergo.htm). In addition, we studied the influence of the SNPs in the B2AR gene on bone mineral density using the meta-analysis of GWA data of the GEFOS consortium (www.gefos.org).

The study was carried out in accordance with the principles of the Declaration of Helsinki. The Institutional Review Boards of the University Medical Center Utrecht (UCP) and of the Erasmus Medical Center (Rotterdam Study) in the Netherlands granted approval for the study. All subjects provided written informed consent. For the GEFOS Consortium, all studies were approved by their respective institutional ethics review committees, and all participants provided written informed consent.

\section{Study populations}

\section{Utrecht cardiovascular pharmacogenetics cohort}

Design and population The Utrecht Cardiovascular Pharmacogenetics cohort enrolled participants from the PharmacoMorbidity Record Linkage System (PHARMO RLS; Institute for Drug Outcome Research, www.pharmo.nl). PHARMO RLS is a registry linking among others pharmacy records to hospital discharge records of over three million individuals in the Netherlands continuously from 1985 onwards. The pharmacy records contain information on drugs prescribed, dispensing date, amount of drug dispensed, dose regimen, and prescription length. Drug prescriptions were coded according to the Anatomical Therapeutic Chemical Classification (ATC), and hospital discharge diagnoses were coded according to the International Classification of Diseases, Ninth Revision, Clinical Modification (ICD-9$\mathrm{CM}$ ). Recruitment of subjects in the UCP was described previously [21]. Briefly, within all patients with hypertension and/or hypercholesterolemia in the PHARMO database, all myocardial infarction patients and matched 
controls (1 up to 12 matching for age, sex, and area of residence) were selected. In addition, a cohort of type 2 diabetes mellitus patients was selected. Community pharmacies recruited these subjects and after informed consent DNA and questionnaire information was collected. All patients selected in the context of these studies were used in the final UCP cohort $(N=5126)$, and 2775 subjects had complete information on the relevant SNPs and medication. Patients were enrolled between 1985 and 2005, and median follow-up was 12 years (IQR 10.5-16.3 years).

Genotyping Participants either collected a buccal cell sample as described previously [22] or received an Oragene collection kit (DNA Genotek, Ottawa, Canada). DNA was extracted according to the manufacturer's instructions. Genotyping was performed with the Illumina (Illumina Inc. San Diego, CA, USA) IBS Candidate Gene array version 3, representing 53, 831 SNPs [23]. SNPs with a call rate $<95 \%$, related samples, contaminated samples, and population outliers were excluded using PLINK [24] and EIGENSTRAT [25].

Case definition Cases were defined by fracture during followup, and this was assessed by first hospital admission for fracture (ICD-9-CM codes 800 to 829). We distinguished the skull (800-804), vertebra (805-806), rib (807), pelvis (808), clavicula (810), scapula (811), humerus (812), arm (813), hand (814-817), hip (820-821), patella (822), leg (823824), foot (825-826), and unspecified (809, 818-819, 827829 ) fractures. All other subjects were defined as controls.

Determinants Age was determined at baseline. Medication use was classified as present if used ever during follow-up.

\section{Rotterdam study}

Design and population The Rotterdam Study is a prospective, population-based cohort initiated to study the determinants of chronic diseases, including osteoporosis. The study design has been described previously [26]. Briefly, the cohort included inhabitants 45 years of age and over of the Ommoord district in the city of Rotterdam in the Netherlands from 1990 onwards. To the original cohort (Rotterdam Study I), two extensions were added (Rotterdam Study II and Rotterdam Study III) in 2000 and 2006 and the total cohort now includes almost 15,000 individuals. At baseline, a home interview on medical history, risk factors for chronic diseases, and medication use was taken by trained interviewers and subjects underwent a clinical examination and laboratory and radiological investigations in a research center, and these examinations were repeated every 3 to 4 years. Of 10,768 subjects, medical information and relevant SNPs were complete and these were included in the present analysis,
Genotyping Rotterdam Study samples were genotyped with the Illumina (Illumina Inc. San Diego, CA, USA) Infinium HumanHap550 HumanHap610 Beadchips. Participants missing DNA or information on body weight and height and samples with gender mismatch with typed X-linked markers, excess autosomal heterozygosity $>0.336 \sim$ FDR $>0.1 \%$, duplicates and/or first- or second-degree relatives using IBS probabilities $>97 \%$ and ethnic outliers using IBS distances $>3$ SD from PLINK [25] were excluded. SNPs with a call rate $<97.5 \%$ and minor allele frequency $<0.01$ were excluded. Next, the data were imputed with reference to the International HapMap Project [27] (CEU panel release 22), and SNPs with an imputation quality of $R^{2}<0.3$ were removed. This resulted in a total of 2,448,227 SNPs in Rotterdam Study I, 2,448,227 SNPs in Rotterdam Study II, and 2,448,227 SNPs in Rotterdam Study III. rs1042713 was directly genotyped, and rs 1042714 ( $R^{2}$ quality score 0.97 in all three cohorts) and rs 1800888 ( $R^{2}$ quality score ranged from 0.63 to 0.74 ) were imputed.

Case definition Cases were defined by fracture during followup. Fractures were assessed in the Rotterdam Study I and Study II by X-ray examinations (digitalized Fuji FCR system (FUJIFILM Medical Systems)) of vertebral bodies, hips, knees, and hand/wrist performed during the periodic examinations. Incident clinical fractures were obtained from computerized records of the general practitioners and hospital registries which were regularly checked by research physicians who reviewed and coded the fracture information [26]. In the Rotterdam Study III, fracture was assessed by vertebral fracture assessment using dual-energy X-ray absorptiometry. All other subjects were defined as controls.

Determinants Age and medication use was determined at baseline.

\section{GEFOS}

Design GEFOS or the Genetic Factors for Osteoporosis Consortium is a collaboration of several international research groups studying the genetics of osteoporosis using metaanalysis of GWA data with high-density SNP arrays. GEFOS has released summary data from their 2012 meta-analyses on femoral neck and lumbar spine bone mineral density tested in 32,961 subjects included from 17 studies (http://www.gefos. org/?q=content/data-release).

Genotyping In brief, genotyping and imputation were performed using standard protocols to facilitate metaanalysis, and quality control was carried out for each study independently. An extensive description can be found in [28]. 
Bone mineral density assessment Lumbar spine and femoral neck bone mineral density were measured in all cohorts using dual-energy X-ray absorptiometry following standard protocols, described in detail in [28].

\section{Data analysis}

Analyses were performed with SPSS for Windows (version 19.0; SPSS Inc., Chicago, IL) for UCP and MACH2DAT [29] run on the GRIMP web-based interface [30] for the Rotterdam Study. Differences between cases and controls were tested with a Student's $t$ test. To assess the association between genotypes and fracture risk, logistic regression analysis was used. The analysis of the Rotterdam Study was adjusted for age, sex, length, and weight. To generate adjusted odds ratios in the UCP analysis, we included sex as a categorical variable and age as a categorical variable since the relation with fracture risk was non-linear and medication use as a categorical variable. The following medication groups were added to the model: glucocorticoids, bone-modifying drugs, anti-depressants, anti-epileptics, benzodiazepines, non-steroidal anti-inflammatory drugs, antidiabetics, antihypertensives (ACE inhibitors, AT2 antagonists, diuretics, alpha blockers, and calcium antagonists), and beta-blockers. There was no deviation from additivity; therefore, we used an additive genetic model. To test for haplotype effects in the UCP cohort, we used R statistical software for Windows (version 2.15 [31], package: Haplostats [32]). Meta-analysis was performed using Review Manager (version 5.2, Copenhagen: The Nordic Cochrane Centre, The Cochrane Collaboration 2012). Inverse variance with fixed effect was used to estimate the pooled odds ratio and the $95 \%$ confidence interval. All tests were two-sided, and a $p$ value of $<0.05$ was considered significant. In GEFOS, genome-wide association analysis for FN- and LS-BMD was carried out using sex-specific and age- and weight- and principal component-adjusted standardized residuals assuming an additive genetic model [28]. The final data files included $p$ values after meta-analysis using regression coefficients (beta and standard error) and after correction for inflation of test statistics using genomic control both at the individual study level and again after meta-analysis.

\section{Power calculation}

With the present sample size of 2617 controls and 158 cases (ratio 16.6) in the UCP Study, odds ratios larger than 1.4 and 3.1 could be detected with $80 \%$ power for SNPs with minor allele frequencies of 0.37 and 0.01 , respectively. In the Rotterdam Study, the sample size of 8559 controls and 2209 cases (ratio 3.9) allows odds ratios larger than 1.1 and 1.53 to be detected with $80 \%$ power for SNPs with a MAF of 0.37 or 0.01 , respectively. For both calculations, a logistic regression model, an additive genetic model, and a two-sided significance level of 0.05 were used.

\section{Results}

Study populations

The UCP cohort consisted of 158 cases and 2617 controls. The Rotterdam Study I included 1575 cases and 4117 controls, Rotterdam Study II 129 cases and 2021 controls, and Rotterdam Study III 505 cases and 2421 controls. Characteristics of the cases and controls per cohort are shown in Table 1 . Cases were significantly more likely to be female and older compared to controls, as expected. Furthermore, in the UCP cohort, cases more often used sleep and antipsychotic medication and non-steroidal anti-inflammatory drugs than controls, although absolute numbers of users were small. Conversely, controls were prescribed significantly more frequently beta-blockers and other antihypertensive and antidiabetic medication. Corticosteroid and bone-modifying drug prescriptions were rare among cases and controls. Genotype did not deviate from Hardy-Weinberg equilibrium. Minor allele frequencies were 0.37 (rs1042713 A allele), 0.45 (rs1042714 $\mathrm{G}$ allele), and 0.01 (rs1800888 T allele) both in the UCP, Rotterdam Study, and GEFOS, which is in accordance with previously published reports [10].

Beta-2 adrenergic receptor genotype and fracture

In UCP, 158 fractures were recorded, one third of which were hip fractures, one of the major osteoporotic fractures. In the Rotterdam Study I, 1575 fractures were recorded, of which vertebral fractures accounted for a quarter and wrist and hip fractures combined for a third of all fractures. The Rotterdam Study II contained 129 fractures, a quarter of which were wrist and hip fractures and almost $20 \%$ vertebral fractures. Five hundred fifty fractures were included in the Rotterdam Study III, all of which were vertebral fractures (Table 2).

We did not find an association between B2AR genotype and fracture neither in the UCP cohort nor in the Rotterdam Study (Table 3). In UCP, we adjusted for age, sex, and medication use, and we performed a haplotype analysis since strong linkage disequilibrium exists between the SNPs; however, the outcome remained the same. In UCP, we also analyzed the data as a cohort study; however, the fracture relative risks using Cox proportional hazard models were similar to the odds ratios. Meta-analysis of the combined nested casecontrol studies estimated a pooled odds ratio of 0.98 (95\% CI $0.91-1.05, p=0.52), 1.04(0.97-1.12, p=0.28)$, and 1.16 $(0.83-1.62, p=0.38)$ for $\mathrm{rs} 1042713$, rs 1042714, and rs1800888 per copy of the minor allele, respectively (Fig. 1). 
Table 1 Characteristics cases and controls per cohort

\begin{tabular}{|c|c|c|c|c|c|c|c|c|c|c|c|c|}
\hline & \multicolumn{3}{|l|}{$\mathrm{UCP}$} & \multicolumn{3}{|c|}{ Rotterdam Study I } & \multicolumn{3}{|c|}{ Rotterdam Study II } & \multicolumn{3}{|c|}{ Rotterdam Study III } \\
\hline & Control & Case & $p$ value & Control & Case & $p$ value & Control & Case & $p$ value & Control & Case & $p$ value \\
\hline Number & 2617 & 158 & & 4117 & 1575 & & 2021 & 129 & & 2421 & 505 & \\
\hline Sex, $\%$ male & 71 & 53 & $<0.001$ & 47 & 27 & $<0.001$ & 46 & 31 & $<0.001$ & 42 & 54 & $<0.001$ \\
\hline Age mean, years (SD) & $58(10.7)$ & $60(11.1)$ & 0.009 & $68(8.8)$ & $70(8.6)$ & $<0.001$ & $65(7.8)$ & $68(9.1)$ & $<0.001$ & $57(6.6)$ & $58(7.4)$ & 0.007 \\
\hline \multicolumn{13}{|l|}{ Medication use, $\%$} \\
\hline Beta-blockers & 79 & 58 & $<0.001$ & 15 & 13 & 0.080 & 15 & 16 & 0.519 & 14 & 17 & 0.096 \\
\hline Other antihypertensives & 77 & 65 & 0.001 & 14 & 12 & 0.042 & 1 & 2 & 0.055 & 0 & 1 & 0.053 \\
\hline Corticosteroids & 8 & 10 & 0.443 & 2 & 2 & 1.000 & 1 & 2 & 0.078 & 1 & 1 & 0.980 \\
\hline Bone-modifying drugs & 8 & 6 & 0.754 & 0 & 0 & NA & 1 & 2 & 0.262 & 1 & 3 & $<0.001$ \\
\hline Antidiabetic drugs & 31 & 18 & $<0.001$ & 4 & 5 & 0.093 & 5 & 8 & 0.025 & 4 & 6 & 0.354 \\
\hline Antidepressant drugs & 6 & 7 & 0.604 & 2 & 2 & 0.535 & 5 & 6 & 0.530 & 7 & 6 & 0.449 \\
\hline Antipsychotic drugs & 1 & 1 & 1.0 & 14 & 18 & $<0.001$ & 10 & 12 & 0.152 & 10 & 6 & 0.006 \\
\hline Antiepileptic drugs & 4 & 4 & 0.503 & 0 & 1 & 1.000 & 14 & 17 & 0.840 & 14 & 26 & 0.074 \\
\hline Sleep medication & 15 & 22 & 0.017 & 14 & 15 & 0.604 & 13 & 20 & 0.006 & 9 & 6 & 0.038 \\
\hline NSAIDs & 10 & 16 & 0.030 & 25 & 26 & 0.365 & 11 & 10 & 0.707 & 14 & 10 & 0.018 \\
\hline Immunosuppressive drugs & 1 & 3 & 0.125 & 0 & 0 & 1.000 & 0 & 0 & NA & 1 & 1 & 0.925 \\
\hline
\end{tabular}

Characteristics of the cases and controls of the UCP and Rotterdam Study cohorts

$N A$ not applicable

Beta-2 adrenergic receptor genotype and bone mineral density

The GEFOS consortium reported $p$ values after meta-analysis for FN-BMD of 0.924, 0.852, and 0.737 and for LS-BMD of $0.635,0.364$, and 0.346 for rs1042713, rs1042714, and rs1800888, respectively.

Table 2 Fracture type

\begin{tabular}{lrlll}
\hline & $\begin{array}{l}\text { UCP } \\
(N=158)\end{array}$ & $\begin{array}{l}\text { RS-I } \\
(N=1575)\end{array}$ & $\begin{array}{l}\text { RS-II } \\
(N=129)\end{array}$ & $\begin{array}{l}\text { RS-III } \\
(N=505)\end{array}$ \\
\hline Skull, $N(\%)$ & $6(4)$ & $56(3)$ & $2(1)$ & ND \\
Vertebrae & $8(5)$ & $509(25)$ & $30(18)$ & $505(100)$ \\
Rib & $19(12)$ & $82(4)$ & $11(7)$ & ND \\
Pelvis & $5(3)$ & $61(3)$ & $4(2)$ & ND \\
Clavicula & $3(2)$ & ND & ND & ND \\
Scapula & 0 & ND & ND & ND \\
Humerus & $4(3)$ & $149(7)$ & $10(6)$ & ND \\
Arm & $14(9)$ & $138(7)$ & $10(6)$ & ND \\
Wrist & ND & $329(16)$ & $26(16)$ & ND \\
Hand & $9(6)$ & $127(6)$ & $20(12)$ & ND \\
Hip & $54(34)$ & $355(17)$ & $16(10)$ & ND \\
Patella & $6(4)$ & ND & ND & ND \\
Leg & $27(17)$ & $100(5)$ & $18(11)$ & ND \\
Foot & $2(1)$ & $57(3)$ & $8(5)$ & ND \\
Unspecified & $1(1)$ & $90(4)$ & $12(7)$ & ND \\
\hline
\end{tabular}

Specification of fracture types per cohort in number and percentage $N D$ not determined, $R S$ Rotterdam Study

\section{Discussion}

In both the Utrecht Cardiovascular Pharmacogenetics and the Rotterdam Study cohorts, there were no associations of polymorphisms in the beta- 2 adrenergic receptor with fracture risk. In the GEFOS consortium, there was also no association of B2AR alleles with bone mineral density.

The B2AR is involved in bone metabolism in rodents. B2AR knockout mice have an increased bone mass and treatment with beta-blockers or beta-agonists increases and decreases bone mass respectively [1,33-36]. The B2AR gene is highly evolutionary conserved; the mouse and human genes are $88 \%$ similar (comparison based on amino acids), and this also applies to the region surrounding the polymorphisms (http://genome.ucsc.edu/cgi-bin/hgTracks?db= hg19\&position=chr5\%3A148206156-148208197\&hgsid= 406908755_GVOKV49jJeWv01Nk5TyiXyon0z8p). In humans, the role of the B2AR in bone metabolism remains speculative. Epidemiological studies investigating the association between beta-blocker treatment and fracture risk presented inconclusive results, although a recent metaanalysis showed some fracture reduction with beta-blocker treatment [2]. Two recent studies support a role of the SNS in the regulation of human bone metabolism. We showed that bone resorption is increased in pheochromocytoma patients and normalized following adrenalectomy [37]. Pheochromocytomas are tumors of the adrenal gland, producing catecholamines, the natural ligands of adrenergic receptors. Farr et al. showed that sympathetic activity, as measured with 
Table 3 Genotype and fracture

\begin{tabular}{|c|c|c|c|c|c|c|c|c|c|}
\hline & \multicolumn{6}{|l|}{ UCP } & \multicolumn{3}{|c|}{ Rotterdam Study } \\
\hline & \multicolumn{6}{|l|}{ Odds ratio } & \multicolumn{3}{|c|}{ Odds ratio } \\
\hline & Crude estimate & $95 \% \mathrm{CI}$ & $p$ value & Adjusted estimate & $95 \% \mathrm{CI}$ & $p$ value & Estimate & $95 \% \mathrm{CI}$ & $p$ value \\
\hline rs1042713 & 0.94 & $0.74-1.19$ & 0.591 & 0.93 & $0.73-1.18$ & 0.545 & 0.98 & $0.91-1.06$ & 0.634 \\
\hline rs1042714 & 1.14 & $0.91-1.43$ & 0.262 & 1.16 & $0.92-1.46$ & 0.223 & 1.03 & $0.96-1.11$ & 0.372 \\
\hline rs1800888 & 0.58 & $0.14-2.38$ & 0.445 & 0.62 & $0.15-2.65$ & 0.523 & 1.21 & $0.86-1.71$ & 0.275 \\
\hline
\end{tabular}

Odds ratios were calculated per copy of the minor allele (rs1042713 Arg/Gly, rs1042714 Gln/Glu, and rs1800888 Thr/Ile)

microneurography, was inversely associated with trabecular microstructure and bone strength in women [38]. Although both studies indicated that the SNS is involved in the regulation of human bone metabolism, they provided no information on the type of adrenergic receptor involved in the signal transduction from the SNS to bone cells. In mice, knockout of adrenergic receptors, including beta-1, beta-2 [39], beta-3 [40], alpha-2A, and alpha-2C [41], results in distinct bone phenotypes, but the bone cell-specific effect has only been demonstrated for the B2AR. The type of adrenergic receptor involved in human bone metabolism remains largely unknown. Our data do not support a critical role for the B2AR.

Polymorphisms in the B2AR gene are functionally relevant in vitro and in vivo [12] in diverse (patho)physiological processes. Mitchell et al. examined the genetics of heterotopic ossification, a skeletal complication in trauma and surgery patients, and identified an increased risk with a polymorphism (rs1042714) in the B2AR gene [42]. This suggests an effect of polymorphisms in the B2AR gene on bone metabolism. A genome-wide association study on bone mineral density has been performed, and the identified loci have been tested for an association with fracture risk, but the B2AR gene was not identified as a significant contributor in this study [28]. However, this does not completely exclude the possibility that polymorphisms in the B2AR gene are involved in bone metabolism. Liu et al. clearly showed in a set of elegant theoretical analyses using simulation studies that the power to identify certain loci depends, among others, on the number of causal SNPs, the effect size of the SNP, and the degree of heterogeneity of the studies [43]. Considering that osteoporosis is a multifactorial disease with probably many causal SNPs differing in effect size [44] and a considerable amount of heterogeneity in the GWAS populations, it remains possible that polymorphisms in the B2AR gene play a role in bone metabolism without being identified in a GWAS analysis. Therefore, candidate gene studies such as ours, based on sound animal experimental evidence, are still important to perform and report.

There are several limitations to this study. Subjects in the UCP cohort had an increased cardiovascular risk, and many were receiving beta-blockers ( $79 \%$ of controls and $58 \%$ of cases), which may have blurred an effect of the polymorphisms. Since $90 \%$ of the beta-blockers prescribed were beta- 1 selective with a low affinity for the beta- 2 adrenergic receptor, the effect on the association between polymorphisms and fracture risk is probably limited. In addition, the lack of association did not change by adjusting the analysis for the use of beta-blockers (Table 3). In the UCP cohort, vertebral
Fig. 1 Forest plots meta-analysis UCP and Rotterdam Study cohorts for polymorphisms in the $\mathrm{B} 2 \mathrm{AR}$ and fracture

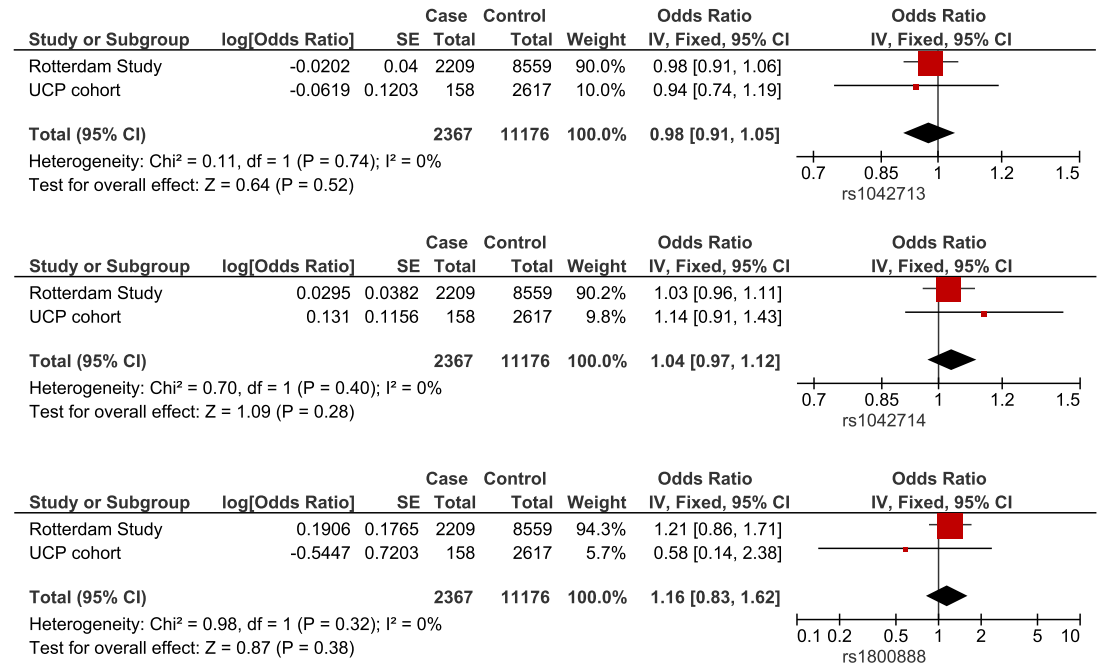


fractures seem underrepresented. This is probably due to the relatively young age of the cohort (mean 58 years) and the definition of fracture based on hospital discharge code; vertebral fracture patients are not routinely admitted to the hospital and mostly treated as outpatients. The Rotterdam Study cohorts, in contrast, contain many fracture patients diagnosed based on interviewing, status reviews, and imaging. The follow-up of the Rotterdam Study I comprises over 20 years of follow-up of inhabitants aged $>55$ years whereas the follow-up of the Rotterdam Study II participants started in 2000; this explains the difference in fracture rate between these populations. The Rotterdam Study III population, started in 2006 at a younger age of 45, underwent standard X-ray examinations of vertebral bodies and thus contains only vertebral fractures, underestimating the true fracture rate. However, vertebral fractures are highly representative of osteoporotic fractures, and the association results for this cohort are not different from the other two cohorts.

Overall, the populations of the UCP and Rotterdam Study were comparable, population-based prospective cohorts of middle-aged subjects. Therefore, in combination, the two cohorts provide a relevant population with an adequate sample size to investigate the hypothesis. However, some information on subject characteristics, such as vitamin D levels, smoking, BMI, prior fracture, and alcoholism, was not fully available in both cohorts, and therefore, we could not perform these secondary analyses. In addition, medication use was determined at baseline in the Rotterdam Study, and with over 20 years of follow-up, this could be very different at the time of fracture; therefore, we did not perform a medication-adjusted analysis for the Rotterdam Study. In the UCP cohort, medication use was determined as present if used during follow-up; therefore, all medication was included. This seems a reliable method for patients suffering from chronic diseases such as hypertension, diabetes, and epilepsy, which generally are long-term medication users, but could influence the results for incident medications such as sleep medication, known to increase fracture risk. However, we did observe a higher percentage of sleep medication use in cases, and considering the crude and adjusted odds ratio's for the associations between fracture and the polymorphisms, an effect of medication does not seem very likely.

The Rotterdam Study included prevalent radiographic vertebral fractures (diagnosed at the start of the study, so there is difficulty in defining follow-up time) and incident fractures (not only clinical fractures occurring during the course of the study but also radiographic vertebral fractures at the follow-up visit after 4 to 7 years, of which a significant proportion is asymptomatic, and thus, determining the exact time of fracture is impossible). Therefore, we chose to analyze the data of the Rotterdam Study as a case-control study. In addition, application of a Cox proportional hazard model to imputed SNP data requires special methods. The UCP cohort included incident fractures, occurring during the course of the study with accurate assessment of the fracture date from the hospital discharge database. Therefore, we re-analyzed the data of the UCP cohort using a Cox proportional hazard model, but this did not change the results.

Finally, although we did not observe any effect of polymorphisms in the B2AR gene on fracture risk and bone mineral density, this does not exclude the possibility of an effect of these polymorphisms through interaction with other, as yet, unknown genes. The original studies in mice were performed in one strain of mice, with the same genetic background. In humans of course, this is very different and it is difficult to control for variations in genetic background possibly affecting the effect of the gene on the outcome. We did analyze haplotypes, which could account for some genetic background variance; however, this did not change the results.

Furthermore, according to the GWAS studies on fracture, fracture risk is probably poly-genetically determined, and thus, interaction of the B2AR gene with other genes is possible. However, the animal studies showed profound influence on bone remodeling by the B2AR itself, and we know that the $\mathrm{B} 2 \mathrm{AR}$ is highly conserved among humans and mice. In addition, we know that polymorphisms in the B2AR by itself influence receptor function. Therefore, if the B2AR influences human bone remodeling, we expected at least some effect of these polymorphisms on fracture risk and bone mineral density.

During the last decade, several lines of research have shown a role of the beta- 2 adrenergic receptor in bone metabolism in rodents. In humans, there is convincing evidence that the sympathetic nervous system influences bone remodeling, although the exact mechanism is still unclear. In the present study, we aimed to elucidate the role of the beta-2 adrenergic receptor by investigating the effect of polymorphisms on fracture risk in two population-based cohorts and on bone mineral density using GWA data, but we did not find an association. For the future, the challenge remains to identify the exact pathway from the sympathetic nervous system to bone and to unravel this complex mechanism.

Acknowledgments The Netherlands Organization for Health Research and Development (ZonMw) provided funding for the analysis of the UCP database. The generation and management of GWAS genotype data for the Rotterdam Study were supported by a Netherlands Organization for Scientific Research (NWO) Investments grant (nr. 175.010.2005.011, 911-03-012). This study was also supported by the Research Institute for Diseases in the Elderly (014-93-015; RIDE2), the Netherlands Genomics Initiative (NGI)/NWO project no. 050-060-810, the Netherlands Forensic Institute, and by a grant from the NGI/NWO within the framework of the Forensic Genomics Consortium Netherlands. The Rotterdam Study is funded by the Erasmus University Medical Center, the Erasmus University Rotterdam, ZonMw, the RIDE, the Ministry of Education, Culture and Science, the Ministry for Health, Welfare and Sports of the Netherlands, the European Commission (DG XII), and the Municipality of Rotterdam. GEFOS is a European Union Seventh Framework Package funded project registered under grant agreement number: FP7-HEALTH- 
F2-2008-201865-GEFOS. A list of members of the GEFOS consortium who participated in the creation of this dataset can be found online (http:// www.gefos.org/?q=content/data-release).

\section{Conflicts of interest None.}

Open Access This article is distributed under the terms of the Creative Commons Attribution Noncommercial License which permits any noncommercial use, distribution, and reproduction in any medium, provided the original author(s) and the source are credited.

\section{References}

1. Kajimura D, Hinoi E, Ferron M, Kode A, Riley KJ, Zhou B, Guo XE, Karsenty G (2011) Genetic determination of the cellular basis of the sympathetic regulation of bone mass accrual. J Exp Med

2. Toulis KA, Hemming K, Stergianos S, Nirantharakumar K, Bilezikian JP (2013) +-Adrenergic receptor antagonists and fracture risk: a meta-analysis of selectivity, gender, and site-specific effects. Osteoporos Int 1-9

3. Rosenbaum DM, Rasmussen SGF, Kobilka BK (2009) The structure and function of G-protein-coupled receptors. Nature 459:356-63

4. Reihsaus E, Innis M, MacIntyre N, Liggett SB (1993) Mutations in the gene encoding for the +2 -adrenergic receptor in normal and asthmatic subjects. Am J Respir Cell Mol Biol 8:334-39

5. Panebra A, Wang WC, Malone MM, Pitter DR, Weiss ST, Hawkins GA, Liggett SB (2010) Common ADRB2 haplotypes derived from 26 polymorphic sites direct beta2-adrenergic receptor expression and regulation phenotypes. PLoS One 5:e11819

6. Liggett SB (2000) Pharmacogenetics of beta-1- and beta-2adrenergic receptors. Pharmacology 61:167-73

7. Green SA, Cole G, Jacinto M, Innis M, Liggett SB (1993) A polymorphism of the human beta 2 -adrenergic receptor within the fourth transmembrane domain alters ligand binding and functional properties of the receptor. J Biol Chem 268:23116-21

8. Green SA, Turki J, Innis M, Liggett SB (1994) Amino-terminal polymorphisms of the human. beta 2-Adrenergic receptor impart distinct agonist-promoted regulatory properties. Biochemistry 33:9414-19

9. Turki J, Lorenz JN, Green SA, Donnelly ET, Jacinto M, Liggett SB (1996) Myocardial signaling defects and impaired cardiac function of a human beta 2-adrenergic receptor polymorphism expressed in transgenic mice. Proc Natl Acad Sci 93:10483-88

10. Small KM, McGraw DW, Liggett SB (2003) Pharmacology and physiology of human adrenergic receptor polymorphisms. Annu Rev Pharmacol Toxicol 43:381-411

11. Ahles A, Engelhardt S (2009) Polymorphisms determine betaadrenoceptor conformation: implications for cardiovascular disease and therapy. Trends Pharmacol Sci 30:188-93

12. Leineweber K, Heusch G (2009) Beta 1- and beta 2-adrenoceptor polymorphisms and cardiovascular diseases. Br J Pharmacol 158: 61-69

13. Brodde OE (2008) Beta1- and beta2-adrenoceptor polymorphisms and cardiovascular diseases. Fundam Clin Pharmacol 22:107-25

14. Johnson JA, Liggett SB (2011) Cardiovascular pharmacogenomics of adrenergic receptor signaling: clinical implications and future directions. Clin Pharmacol Ther 89:366-78

15. Martinez FD, Graves PE, Baldini M, Solomon S, Erickson R (1997) Association between genetic polymorphisms of the beta2adrenoceptor and response to albuterol in children with and without a history of wheezing. J Clin Invest 100:3184-88

16. Lipworth BJ, Basu K, Donald HP, Tavendale R, Macgregor DF, Ogston SA, Palmer CNA, Mukhopadhyay S (2013) Tailored second-line therapy in asthmatic children with the Arg16 genotype. Clin Sci 124:521-28

17. Large V, Hellstrom L, Reynisdottir S, Lonnqvist F, Eriksson P, Lannfelt L, Arner P (1997) Human beta-2 adrenoceptor gene polymorphisms are highly frequent in obesity and associate with altered adipocyte beta-2 adrenoceptor function. J Clin Invest 100:3005-13

18. Kulminski AM, Culminskaya I, Ukraintseva SV, Arbeev KG, Land KC, Yashin AI (2010) Beta2-adrenergic receptor gene polymorphisms as systemic determinants of healthy aging in an evolutionary context. Mech Ageing Dev 131:338-45

19. Adriani KS, Brouwer MC, Baas F, Zwinderman AH, van der Ende A, van de Beek D (2012) Genetic variation in the +'2-adrenocepter gene is associated with susceptibility to bacterial meningitis in adults. PLoS ONE 7:e37618

20. Chu X, Dong Y, Shen M, Sun L, Dong C, Wang Y, Wang B, Zhang K, Hua Q, Xu S, Huang W (2009) Polymorphisms in the ADRB2 gene and Graves disease: a case-control study and a meta-analysis of available evidence. BMC Med Genet 10:26

21. Wieren-de Wijer D, Maitland-van der Zee A-H, Boer A, Stricker B, Kroon A, Leeuw P, Bozkurt O, Klungel O (2009) Recruitment of participants through community pharmacies for a pharmacogenetic study of antihypertensive drug treatment. Pharm World Sci 31:158 64

22. van Wieren-de Wijer DB, Maitland-van der Zee A-H, de Boer A, Kroon AA, de Leeuw PW, Schiffers P, Janssen RG, Psaty BM, van Duijn CM, Stricker BH, Klungel OH (2009) Interaction between the Gly460Trp +,-adducin gene variant and diuretics on the risk of myocardial infarction. J Hypertens 27

23. Keating BJ, Tischfield S, Murray SS, Bhangale T, Price TS, Glessner JT, Galver L, Barrett JC, Grant SFA, Farlow DN, Chandrupatla HR, Hansen M, Ajmal S, Papanicolaou GJ, Guo Y, Li M, DerOhannessian S, de Bakker PIW, Bailey SD, Montpetit A, Edmondson AC, Taylor K, Gai X, Wang SS, Fornage M, Shaikh T, Groop L, Boehnke M, Hall AS, Hattersley AT, Frackelton E, Patterson N, Chiang CWK, Kim CE, Fabsitz RR, Ouwehand W, Price AL, Munroe P, Caulfield M, Drake T, Boerwinkle E, Reich D, Whitehead AS, Cappola TP, Samani NJ, Lusis AJ, Schadt E, Wilson JG, Koenig W, McCarthy MI, Kathiresan S, Gabriel SB, Hakonarson H, Anand SS, Reilly M, Engert JC, Nickerson DA, Rader DJ, Hirschhorn JN, FitzGerald GA (2008) Concept, Design and Implementation of a Cardiovascular Gene-Centric $50 \mathrm{~K}$ SNP Array for Large-Scale Genomic Association Studies. PLoS ONE 3:e3583

24. Purcell S, Neale B, Todd-Brown K, Thomas L, Ferreira MAR, Bender D, Maller J, Sklar P, de Bakker PIW, Daly MJ, Sham PC (2007) PLINK: a tool set for whole-genome association and population-based linkage analyses. Am J Hum Genet 81:559-75

25. Price AL, Patterson NJ, Plenge RM, Weinblatt ME, Shadick NA, Reich D (2006) Principal components analysis corrects for stratification in genome-wide association studies. Nat Genet 38:904-9

26. Hofman A, Murad S, Duijn C, Franco O, Goedegebure A, Arfan Ikram M, Klaver C, Nijsten T, Peeters R, Stricker B, Tiemeier H, Uitterlinden AG, Vernooij M (2013) The Rotterdam Study: 2014 objectives and design update. Eur J Epidemiol 28:889-926

27. (2007) A second generation human haplotype map of over 3.1 million SNPs. Nature 449: 851-61

28. Estrada K, Styrkarsdottir U, Evangelou E, Hsu YH, Duncan EL, Ntzani EE, Oei L, Albagha OME, Amin N, Kemp JP, Koller DL, Li G, Liu CT, Minster RL, Moayyeri A, Vandenput L, Willner D, Xiao SM, Yerges-Armstrong LM, Zheng HF, Alonso N, Eriksson J, Kammerer CM, Kaptoge SK, Leo PJ, Thorleifsson G, Wilson SG, Wilson JF, Aalto V, Alen M, Aragaki AK, Aspelund T, Center JR, Dailiana Z, Duggan DJ, Garcia M, Garcia-Giralt N, Giroux S, Hallmans G, Hocking LJ, Husted LB, Jameson KA, Khusainova R, Kim GS, Kooperberg C, Koromila T, Kruk M, Laaksonen M, LaCroix AZ, Lee SH, Leung PC, Lewis JR, Masi L, MencejBedrac S, Nguyen TV, Nogues X, Patel MS, Prezelj J, Rose LM, 
Scollen S, Siggeirsdottir K, Smith AV, Svensson O, Trompet S, Trummer O, van Schoor NM, Woo J, Zhu K, Balcells S, Brandi ML, Buckley BM, Cheng S, Christiansen C, Cooper C, Dedoussis G, Ford I, Frost M, Goltzman D, Gonzalez-Macias J, Kahonen M, Karlsson M, Khusnutdinova E, Koh JM, Kollia P, Langdahl BL, Leslie WD, Lips P, Ljunggren O, Lorenc RS, Marc J, Mellstrom D, Obermayer-Pietsch B, Olmos JM, Pettersson-Kymmer U, Reid DM, Riancho JA, Ridker PM, Rousseau F, Lagboom PE, Tang NLS, Urreizti R, Van Hul W, Viikari J, Zarrabeitia MT, Aulchenko YS, Castano-Betancourt M, Grundberg E, Herrera L, Ingvarsson T, Johannsdottir H, Kwan T, Li R, Luben R, Medina-Gomez C, Th Palsson S, Reppe S, Rotter JI, Sigurdsson G, van Meurs JBJ, Verlaan D, Williams FMK, Wood AR, Zhou Y, Gautvik KM, Pastinen T, Raychaudhuri S, Cauley JA, Chasman DI, Clark GR, Cummings SR, Danoy P, Dennison EM, Eastell R, Eisman JA, Gudnason V, Hofman A, Jackson RD, Jones G, Jukema JW, Khaw KT, Lehtimaki T, Liu Y, Lorentzon M, McCloskey E, Mitchell BD, Nandakumar K, Nicholson GC, Oostra BA, Peacock M, Pols HAP, Prince RL, Raitakari O, Reid IR, Robbins J, Sambrook PN, Sham PC, Shuldiner AR, Tylavsky FA, van Duijn CM, Wareham NJ, Cupples LA, Econs MJ, Evans DM, Harris TB, Kung AWC, Psaty BM, Reeve J, Spector TD, Streeten EA, Zillikens MC, Thorsteinsdottir U, Ohlsson C, Karasik D, Richards JB, Brown MA, Stefansson K, Uitterlinden AG, Ralston SH, Ioannidis JPA, Kiel DP, Rivadeneira F (2012) Genome-wide meta-analysis identifies 56 bone mineral density loci and reveals 14 loci associated with risk of fracture. Nat Genet 44:491-501

29. Li Y DJAG (2006) Mach 1.0: Rapid haplotype reconstruction and missing genotype inference. Abstract 2290, presented at the annual meeting of the American Society of Human Genetics, New Orleans

30. Estrada K, Abuseiris A, Grosveld FG, Uitterlinden AG, Knoch TA, Rivadeneira F (2009) GRIMP: a web- and grid-based tool for highspeed analysis of large-scale genome-wide association using imputed data. Bioinformatics 25:2750-2752

31. R Core Team (2013) R: A language and environment for statistical computing

32. Sinnwell JP, Schaid DJ (2013) haplo.stats: statistical analysis of haplotypes with traits and covariates when linkage phase is ambiguous

33. Elefteriou F, Ahn JD, Takeda S, Starbuck M, Yang X, Liu X, Kondo H, Richards WG, Bannon TW, Noda M, Clement K, Vaisse C, Karsenty G (2005) Leptin regulation of bone resorption by the sympathetic nervous system and CART. Nature 434:514-20
34. Arai M, Sato T, Takeuchi S, Goto S, Togari A (2013) Dose effects of butoxamine, a selective +2 -adrenoceptor antagonist, on bone metabolism in spontaneously hypertensive rat. Eur J Pharmacol 701:7-13

35. Kondo H, Togari A (2011) Continuous treatment with a low-dose + agonist reduces bone mass by increasing bone resorption without suppressing bone formation. Calcif Tissue Int 88:23-32

36. Bonnet N, Benhamou CL, Brunet-Imbault B, Arlettaz A, Horcajada MN, Richard O, Vico L, Collomp K, Courteix D (2005) Severe bone alterations under beta 2 agonist treatments: bone mass, microarchitecture and strength analyses in female rats. Bone 37: 622-33

37. Veldhuis-Vlug AG, El Mahdiui M, Endert E, Heijboer AC, Fliers E, Bisschop PH (2012) Bone resorption is increased in pheochromocytoma patients and normalizes following adrenalectomy. J Clin Endocrinol Metab 97:E2093-E2097

38. Farr JN, Charkoudian N, Barnes JN, Monroe DG, McCready LK, Atkinson EJ, Amin S, Melton LJ, Joyner MJ, Khosla S (2012) Relationship of sympathetic activity to bone microstructure, turnover, and plasma osteopontin levels in women. J Clin Endocrinol Metab 97:4219-27

39. Pierroz DD, Bonnet N, Bianchi EN, Bouxsein ML, Baldock PA, Rizzoli R, Ferrari SL (2012) Deletion of +,-adrenergic receptor 1, 2, or both leads to different bone phenotypes and response to mechanical stimulation. J Bone Miner Res 27:1252-62

40. Bouxsein ML, Devlin MJ, Glatt V, Dhillon H, Pierroz DD, Ferrari SL (2009) Mice lacking beta-adrenergic receptors have increased bone mass but are not protected from deleterious skeletal effects of ovariectomy. Endocrinology 150:144-52

41. Fonseca TL, Jorgetti V, Costa CC, Capelo LP, Covarrubias AE, Moulatlet AC, Teixeira MB, Hesse E, Morethson P, Beber EH, Freitas FR, Wang CC, Nonaka KO, Oliveira R, Casarini DE, Zorn TM, Brum PC, Gouveia CH (2011) Double disruption of +'2A- and + 2C -adrenoceptors results in sympathetic hyperactivity and highbone-mass phenotype. J Bone Miner Res 26:591-603

42. Mitchell EJ, Canter J, Norris P, Jenkins J, Morris J (2010) The genetics of heterotopic ossification: insight into the bone remodeling pathway. J Orthop Trauma 24:530-533

43. Liu YJ, Zhang L, Pei Y, Papasian CJ, Deng HW (2013) On genomewide association studies and their meta-analyses: lessons learned from osteoporosis studies. J Clin Endocrinol Metab 98:E1278E1282

44. Ralston SH, Uitterlinden AG (2010) Genetics of osteoporosis. Endocr Rev 31:629-62 